\title{
Summary of NGNP Engineering Analysis Progress in Fiscal Year 2010
}

P. M. Mills

The INL is a

U.S. Department of Energy National Laboratory

operated by

Battelle Energy Alliance

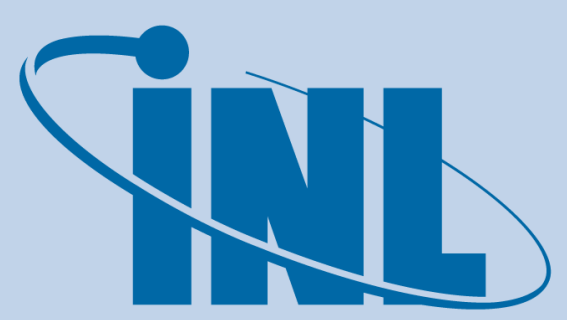

Idaho National Laboratory
September 2010

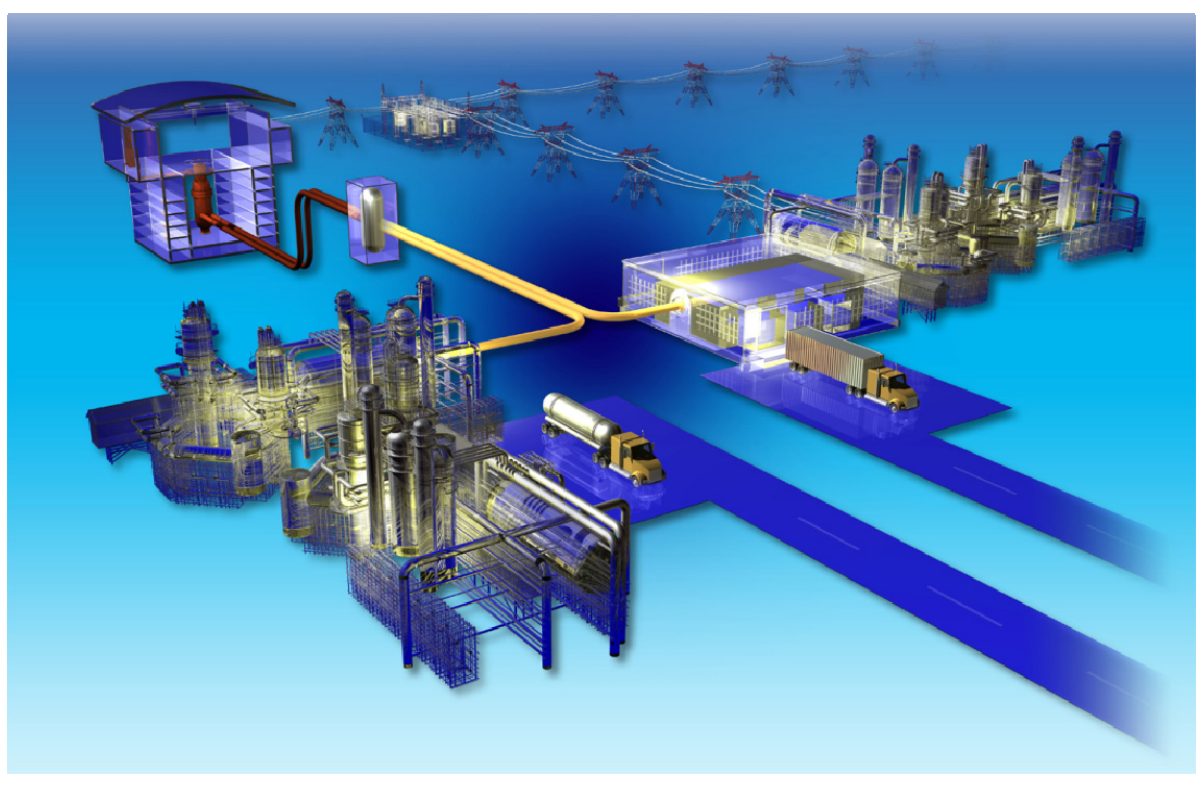




\section{DISCLAIMER}

This information was prepared as an account of work sponsored by an agency of the U.S. Government. Neither the U.S. Government nor any agency thereof, nor any of their employees, makes any warranty, expressed or implied, or assumes any legal liability or responsibility for the accuracy, completeness, or usefulness, of any information, apparatus, product, or process disclosed, or represents that its use would not infringe privately owned rights. References herein to any specific commercial product, process, or service by trade name, trade mark, manufacturer, or otherwise, does not necessarily constitute or imply its endorsement, recommendation, or favoring by the U.S. Government or any agency thereof. The views and opinions of authors expressed herein do not necessarily state or reflect those of the U.S. Government or any agency thereof. 


\title{
Summary of NGNP Engineering Analysis Progress in Fiscal Year 2010
}

\author{
P. M. Mills
}

September 2010

Idaho National Laboratory

Next Generation Nuclear Plant Project

Idaho Falls, Idaho 83415

Prepared for the

U.S. Department of Energy

Office of Nuclear Energy

Under DOE Idaho Operations Office

Contract DE-AC07-05ID14517 

Next Generation Nuclear Plant Project

\title{
Summary of NGNP Engineering Analysis Progress in Fiscal Year 2010
}

\author{
INL/EXT-10-19772
}

September 2010
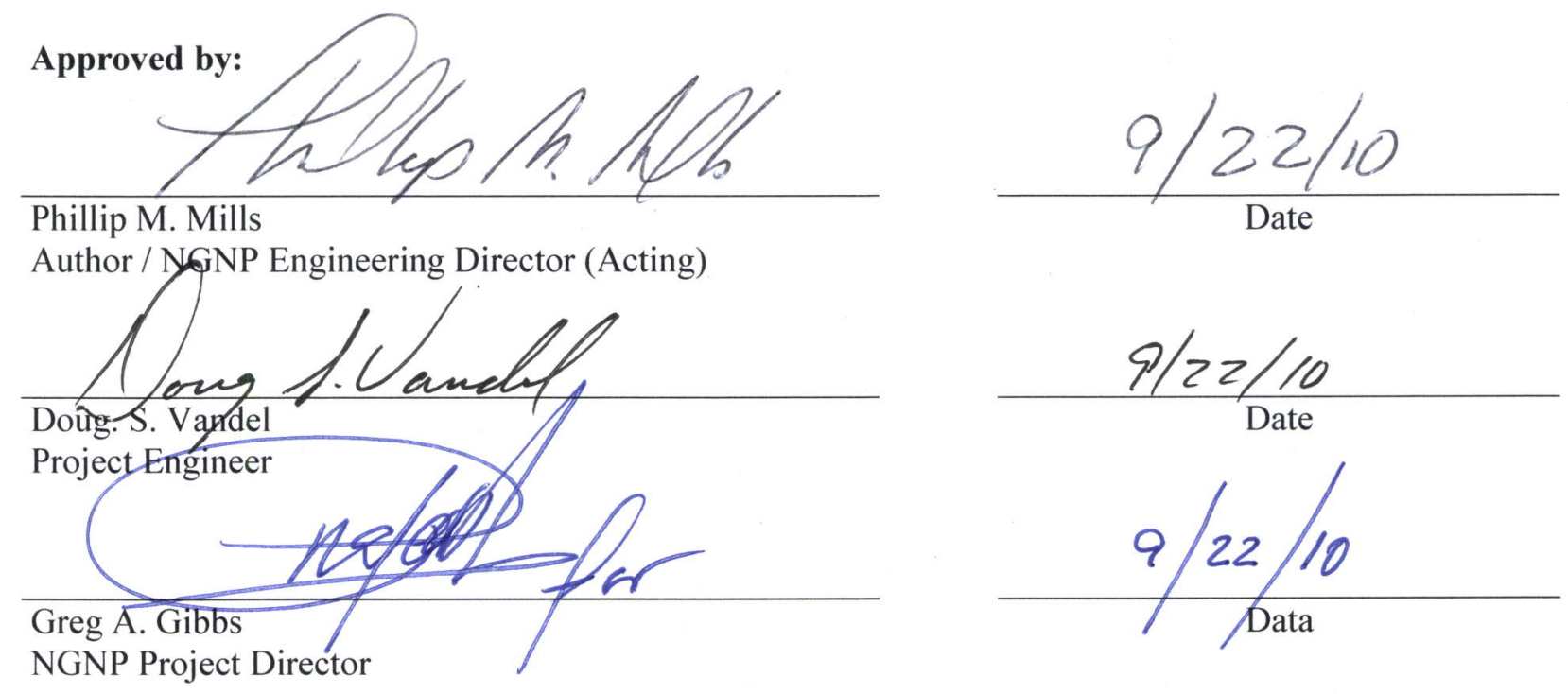



\section{ABSTRACT}

The Engineering Analysis work package accomplished a number of activities for the Next Generation Nuclear Plant (NGNP) Project in FY 2010 that will help inform Licensing, Research and Development, and detailed design activities to be performed during the preliminary design phase in Phase 2 of the NGNP Project. These activities were in the following areas:

- Fission Product Transport

- DDN Update and Consolidation

- Gas Reactor Lessons Learned Review

- Reactor Coolant Chemistry Control

- Resilient Control Systems for High Temperature Gas-cooled Reactors

- Water-ingress Analysis.

In total, the efforts associated with the Engineering Analysis work package accomplished four Level 2 (external) milestones and two Level 4 (internal) milestones. Details of these activities and their associated milestones are presented in this report. 


\section{CONTENTS}

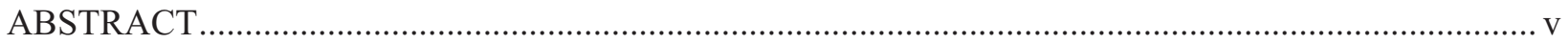

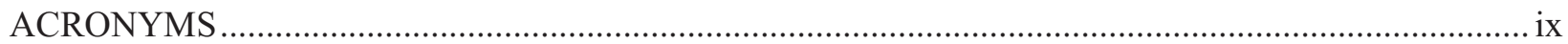

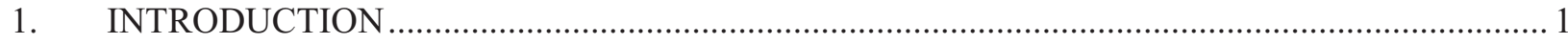

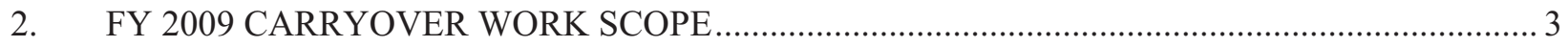

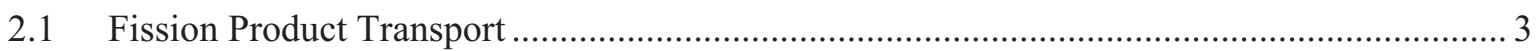

2.1.1 Purpose

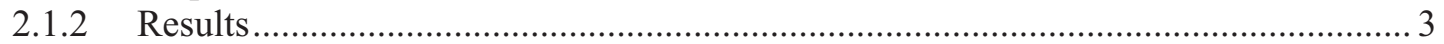

2.2 Design Data Needs Update and Consolidation by Design Suppliers ..................................... 3

2.2.1 Purpose

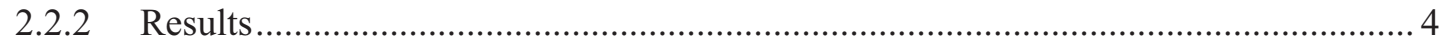

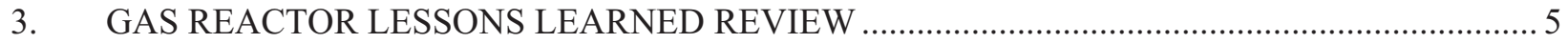

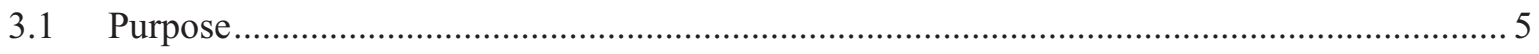

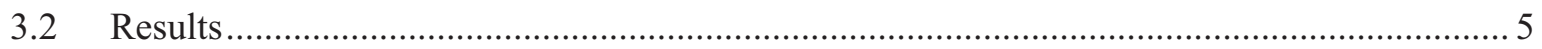

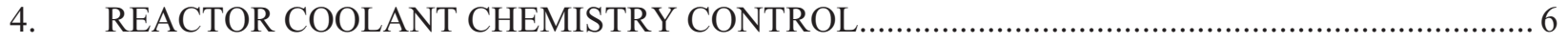

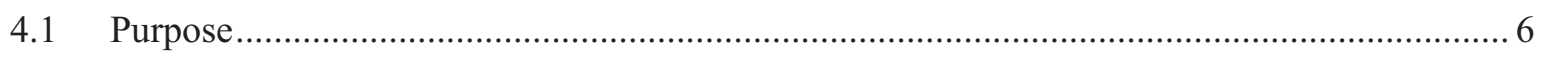

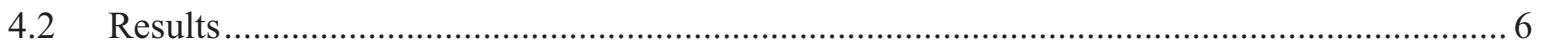

5. RESILIENT CONTROL SYSTEMS FOR HIGH TEMPERATURE GAS-COOLED

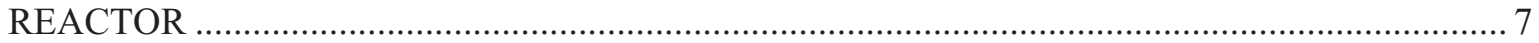

5.1 Purpose

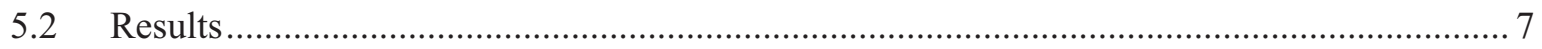

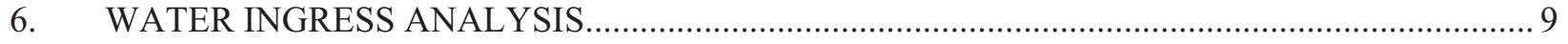

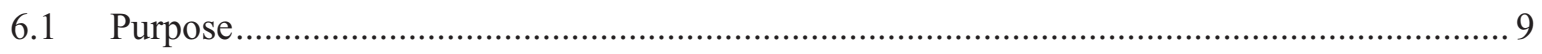

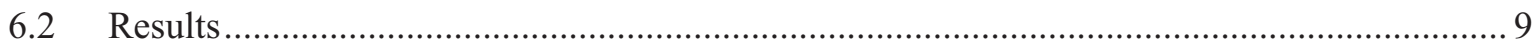

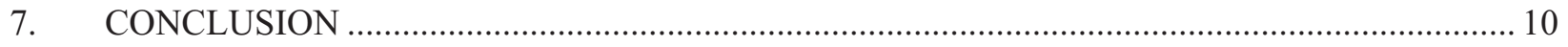

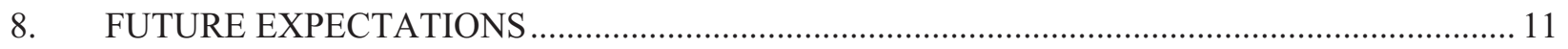

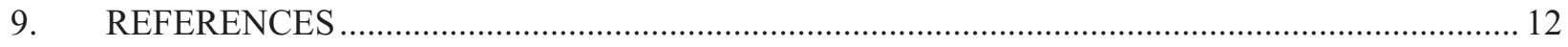




\section{ACRONYMS}

ACTH accident analysis and thermal fluids

BCP Baseline Change Proposal

CPIRT conceptual PIRT

DDN Design Data Need

DOE-ID U.S. Department of Energy Idaho Operations Office

DOE-NE DOE Office of Nuclear Energy

FOA Funding Opportunity Announcement

FY fiscal year

HPS helium purification system

HTGR high temperature gas-cooled reactor

HTTF High Temperature Test Facility

IHX intermediate heat exchanger

I\&C Instrumentation \& Controls

INL Idaho National Laboratory

NGNP Next Generation Nuclear Plant

NRC U.S. Nuclear Regulatory Commission

OSU Oregon State University

PIRT Phenomena Identification and Ranking Table

R\&D research and development

ROT reactor outlet temperature

SAG Senior Advisory Group

SOW Statement of Work

TRISO tri-isotropic (fuel)

WBS Work Breakdown Structure 


\section{Summary of NGNP Engineering Analysis Progress in FY 2010}

\section{INTRODUCTION}

This report summarizes the status of work activities performed in the Next Generation Nuclear Plant (NGNP) Engineering Analysis work package during fiscal year (FY) 2010.

The NGNP Engineering Analysis work package (Idaho National Laboratory [INL] Work Breakdown Structure [WBS] C.Q.10.02.00.01.02) evolved from the original NGNP Engineering Design Development (same INL WBS number) work package intended to direct the design development work scope of the commercial gas reactor supplier teams and which had been utilized during FY 2007 through 2009. An FY 2010 baseline for this commercial supplier support was originally established in this work package via planning packages pending work scope approval. Realizing that conceptual design was to be performed under the Funding Opportunity Announcement (FOA) issued by the U.S. Department of Energy Idaho Operations Office (DOE-ID) on September 18, 2009 (DOE-ID 2009), the proposed work scope was modified based on input from both the DOE Office of Nuclear Energy (NE) Headquarters and DOE-ID during October through December 2009 to remove potential duplications with the FOA conceptual design work activities for Phase 1 of the NGNP Project. The work package was retitled to Engineering Analysis and specific work activities were negotiated and approved by DOE-ID via Baseline Change Proposal (BCP) 10-CQ-005R1 on December 17, 2009. The approved work scope avoided duplication with existing or future FOA directed work, did not include the use of offerors to the FOA as subcontractors, and was to be performed through a combination of INL directly self-performing the tasks, utilization of other national laboratories, utilization of universities, or subcontracting to technical experts that did not participate in the responses to the FOA solicitation.

The work scope included in the Engineering Analysis work package was determined and selected for their attributes that will help to inform Licensing, Research and Development (R\&D), and detailed design activities that will be performed during the preliminary design phase in Phase 2 of the NGNP Project. This work scope includes:

- Gas Reactor Lessons Learned Review

- Reactor Coolant Chemistry Control

- Resilient Control Systems for High Temperature Gas-cooled Reactors

- Support for Oregon State University (OSU) High Temperature Test Facility (HTTF)

- Broaden Process Modeling of Industrial Heat Applications

- FY 2010 Engineering Analysis Summary Report.

The "broaden process modeling of industrial heat applications" work scope was subsequently determined to more properly belong in the Process Heat Applications work package (INL WBS C.Q.10.02.00.01.03) and was consequently moved via BCP 10-CQ-006 with DOE-ID approval on February 11, 2010.

The "support for OSU HTTF" work scope was problematic because the desired support was to come from the commercial design suppliers that had been offerors to the FOA, and also that the bulk of the funding OSU has received for HTTF was derived from the U.S. Nuclear Regulatory Commission (NRC). This meant there were potential issues with the appearance of conflicts of interest in addition to the restrictions on the use of the design suppliers by DOE. This scope was eventually deleted via BCP 10CQ-008, which was approved by DOE-ID on June 14, 2010. 
The approval of BCP 10-CQ-008 also directed the inclusion of a new work activity for evaluating moisture ingress into the reactor, identifying moisture studies and information to establish data gaps, and determining the R\&D path forward for resolving moisture ingress/attack issues.

The Engineering Analysis work package also included FY 2009 carryover work scope involving the completion of several activities from the original Design Development work package that were carried into FY 2010 from FY 2009. 


\section{FY 2009 CARRYOVER WORK SCOPE}

\subsection{Fission Product Transport}

\subsubsection{Purpose}

Statements of Work (SOW) issued in FY 2009 to the reactor supplier design teams led by Westinghouse and General Atomics each contained a requirement to perform a study, "Source Term \& Fission Product Transport, Decontamination Factor, Dose Analysis" (WBS C.Q.10.20.10.PE.R3G). The intent of this study was to build on previous studies for both the pebble bed and prismatic block reactor designs on the subjects of contamination control and reactor building functions to evaluate potential radionuclide releases and control requirements. This new study was conducted to (1) evaluate steady-state and transient plant conditions for hold-up/plate-out of fission products in key components, (2) establish an initial set of design target allocations for hold-up/plate-out vice releases, (3) estimate total source term and decontamination factors for the reference plant designs, and (4) evaluate allowable releases to meet anticipated dose limits. A side-benefit of this study was to confirm whether the initial performance and quality requirements established for the tri-isotropic (TRISO) fuel to be used in the NGNP were reasonable.

\subsubsection{Results}

The General Atomics team completed their work scope and issued General Atomics report 911168, Technical Basis for NGNP Fuel Performance and Quality Requirements, on September 18, 2009.

The Westinghouse team completed their work scope and issued Westinghouse report NGNP-PLDGEN-RPT-N-00007, Next Generation Nuclear Plant: Plant Level Assessments Leading to Fission Product Retention Allocations, on October 6, 2009.

INL submitted letter CCN 218707, "Completion of Level 2 Milestone - Complete Fission Product Transport Report," to DOE-NE on October 13, 2009, to document the completion of Level 2 Milestone M2GIN07NG0705.

Discussion: The General Atomics and Westinghouse reports established that, although the currently specified quality requirements for the TRISO fuel are appropriate, multiple retention barriers in the design of the NGNP would be required to meet anticipated dose limits. The results of these reports are currently being used in dose estimating activities in the Safety Analysis/Probabilistic Risk Assessment work package, and were also used to inform licensing white papers for NGNP fuel qualification and mechanistic source terms (INL 2010a; INL 2010b) that were reviewed in NRC public meetings on September 1, 2010. Additional effort will be required in this area as the design(s) for the NGNP progress, and a design margin management program will need to be established in order to ensure that allocated margins for the various retention barriers are addressed during their design such that overall anticipated dose limits can be met.

\subsection{Design Data Needs Update and Consolidation by Design Suppliers}

\subsubsection{Purpose}

Design Data Needs (DDNs) are an integral part of the NGNP technical risk management process, and are identified by the reactor designers to specify needed R\&D activities that will generate specific data/information to support resolution of design issues. During the studies following completion of the 
preconceptual design phase, the tracking of applicable DDNs had become complicated by changes to planned reactor outlet temperatures, reference configurations, technology development needs as reflected in Technology Development Roadmap reports, and by individual reports containing revisions to previously specified DDNs, deleting existing DDNs, or adding new ones. NGNP Engineering desired to obtain updated lists of DDNs from the reactor design suppliers and also to establish the lists as configuration managed lists in order to better support identification of definitively needed R\&D tasks and to support refinement of $R \& D$ program plans and ultimately $R \& D$ input to the integrated schedule for the project. SOWs were issued in FY 2009 to the reactor supplier design teams led by Westinghouse, AREVA, and General Atomics that required each reactor supplier to (1) update their existing DDNs or develop new DDNs as necessary to reflect current requirements, reference configurations, and technical development status, (2) consolidate the DDNs into a single configuration managed list, and (3) issue the list as a deliverable to NGNP Engineering.

\subsubsection{Results}

The Westinghouse design team completed their DDN updates and submitted a configuration managed list of DDNs to NGNP Engineering via Westinghouse report NGNP-TDI-GEN-DDN-G-00025, Design Data Needs List for the PBMR, on November 10, 2009. The report forwarded their configuration managed list of DDNs, NGNP-DDN PBMR-LIST-01, Rev. 0. This list includes updates to their preconceptual design report DDNs for a cogeneration plant operating with a Reactor Outlet Temperature in the $750-800^{\circ} \mathrm{C}$ range, such that process steam could be supplied to industrial applications, plus an option for cogenerated electrical power delivery. This listed included refined and new DDNs resulting from various studies conducted after the preconceptual design was complete. Although this list was intended to support a revised reference configuration in which a pebble bed reactor was coupled to a steam generator in the primary loop and the intermediate heat exchanger (IHX) was eliminated, Westinghouse did include their IHX and associated heat transfer system DDNs, in order to support the ultimate higher temperature operation planned for the nth-of-a-kind plant. The reactor power level was not specifically addressed in this DDN list.

The AREVA design team completed their DDN updates and submitted a configuration managed list to NGNP Engineering via AREVA report 12-9124116-000, NGNP - Design Data Needs for AREVA $750^{\circ} \mathrm{C}$ Prismatic Reactor Concept, on October 29, 2009. The reference design parameters used by AREVA for this update were those associated with a first-of-a-kind $625 \mathrm{MWth}$ prismatic block reactor with a reactor outlet temperature (ROT) of $750^{\circ} \mathrm{C}$ in a cogeneration configuration with a conventional steam cycle for power conversion. This report provides a uniform format for AREVA identified DDNs originating from different time frames and efforts.

General Atomics had previously submitted their DDN updates and configuration managed list to NGNP Engineering via letter report on September 22, 2009. The associated reference configuration was for a $550 \mathrm{MWth}$ prismatic block reactor (with stretch capability to $600 \mathrm{MWth}$ ) with a $750^{\circ} \mathrm{C}$ ROT and a conventional steam cycle for power conversion. This report provides a uniform list of General Atomics identified DDNs originating from different time frames and efforts.

Discussion: As the NGNP Project moves forward, the list of applicable DDNs will be a dynamic list because details of the plant designs will be refined and updated. NGNP Engineering anticipates that as part of the deliverables associated with Phase 1 of the FOA, General Atomics will develop an updated DDN list that is based largely on the reference Modular High Temperature Gas-cooled Reactor Plant at a 350 MWth power level. 


\section{GAS REACTOR LESSONS LEARNED REVIEW}

\subsection{Purpose}

The NGNP Project has benefitted from a great deal of technical heritage gained from the design and operation of previous gas reactors and HTGRs. Several generations of gas reactors and HTGRs have been designed, built, and operated worldwide, to date, and significant design planning has been initiated for several variations of both the pebble bed and the prismatic block reactors. Lessons learned that were determined and implemented during actual operation and the progression of later HTGR plants has led to design features pertinent to the NGNP Project, such as the TRISO fuel particle and the steel reactor pressure vessel as opposed to the BISO fuel particles and prestressed concrete reactor vessels used in earlier HTGRs. Although operational experience for the Fort Saint Vrain HTGR was gathered and documented by Oak Ridge National Laboratory in NUREG/CR-6839 (2004), and the Generation IV International Forum and the Independent Technology Review Group relied on historical information for their reviews of technology alternatives for the next generation reactor plants, there had not been a comprehensive effort to research and consolidate lessons learned from experiences gained at the experimental and commercial-scale gas-cooled reactor installations, or from prior design planning for potential future variations of the HTGR. This gas reactor lessons learned review was intended to capture these various experiences and determine which might be relevant to the NGNP Project.

\subsection{Results}

INL report INL/EXT-10-19329, High Temperature Gas-Cooled Reactors Lessons Learned: Global Experiences in High Temperature Gas-Cooled Reactors, was issued on September 15, 2010, and captures these lessons learned and groups them according to pertinent structure, system, and component planned for the NGNP. The report also evaluates these lessons learned and categorizes them regarding whether they apply to NGNP planning or not because of differing plant configurations or design approaches.

INL submitted letter CCN 220870, "Completion of Level 2 Milestone - Issue Gas Reactor Lessons Learned Report," to DOE-NE on September 15, 2010 to document the completion of Level 2 Milestone M2GIN10NG0703a25.

Discussion: Those lessons learned that have the potential for impact on NGNP planning are related to:

- Ingress events such as moisture ingress and air ingress

- Primary coolant bypass flow and impurities

- Fission products release resulting from events beyond design basis

- Fission products release resulting from normal operations

Planning to incorporate these lessons learned into the NGNP Risk Management System as applicable will be addressed in FY 2011. Many aspects of these lessons learned are already included in program plans associated with the NGNP that are issued and managed by the Very High Temperature Reactor Technology Development Office. 


\section{REACTOR COOLANT CHEMISTRY CONTROL}

\subsection{Purpose}

The high temperature operation of the HTGR means that many of the materials within the helium pressure boundary are subjected to degradation mechanisms that are not fully characterized or understood. In addition to mechanical degradation mechanisms caused by operation at temperatures for which material creep or creep fatigue is a concern, there are other potential concerns related to accelerated corrosion of materials at these temperatures caused by unfavorable coolant chemistries or impurities. Although previous HTGR plants have utilized helium purification systems (HPS) and tightly controlled operational chemistry, there is little long-term experience with those high temperature materials being proposed for the NGNP. The purpose of this study was to determine what technical developments have occurred since HPSs were designed for previous HTGRs that might inform HPS design requirements for NGNP. For example, a considerable number of corrosion studies have been performed on various high temperature materials in helium environments with various chemistries at elevated temperatures. This newer work was reviewed to determine how the new information impacts the design requirements for the HPS and chemistry control strategy for the NGNP.

\subsection{Results}

INL report INL/EXT-10-19533, NGNP Reactor Coolant Chemistry Control Study, was issued on August 26, 2010 to document the results of the study. This report documents the designs and target impurity levels for HPSs used in previous HTGRs and current information about target impurity levels for high temperature metals and graphite. The report also provides an approach strategy to chemistry control for the NGNP, including discussions of the locations of primary taps used to siphon primary coolant into the HPS and of the instrumentation necessary to support the control of impurities within desired parameters.

Discussion: The bulk materials used in the primary circuit will largely define coolant chemistry requirements, which are chosen to optimize the operational life of all major components within the primary circuit. For the HTGR designs currently being pursued by the NGNP Project, high-chromium alloys and graphite are the two main types of materials that will drive coolant chemistry requirements. These materials have somewhat differing chemistry control needs. Simply stated, while the metallic components need a small amount of moisture in the coolant to help form and maintain a protective oxide layer, the graphite needs a very dry environment to prevent degradation caused by oxidation. In order to support favorable chemistry with respect to oxidation, the contaminants that are specifically targeted for removal in the HPS will be $\mathrm{H}_{2}, \mathrm{CO}, \mathrm{CO}_{2}, \mathrm{CH}_{4}, \mathrm{H}_{2} \mathrm{O}$, and $\mathrm{N}_{2}$. Impurity levels will be controlled, however, to maintain beneficial balances between some impurities that facilitate the growth of an oxide layer that protects the metallic structures. The most important balance has been determined to be between $\mathrm{CO} / \mathrm{H}_{2} \mathrm{O}$ and $\mathrm{CO} / \mathrm{H}_{2}$.

The planning for reactor coolant chemistry control will be updated and refined as the design of the NGNP progresses and as specific material selections for structures, systems, and components within the primary circuit are made. 


\section{RESILIENT CONTROL SYSTEMS FOR HIGH TEMPERATURE GAS- COOLED REACTOR}

\subsection{Purpose}

Industrial processes and nuclear reactors designed and built in the 1960s, 70s, and early 80s typically employ analog instrumentation with automation to the extent allowed by such systems. With the growth in digital technologies and obsolescence of analog instruments and controls, many industrial plants have retrofitted to digital instrumentation either plant-wide or one system at a time. This method of implementation lends itself to employing islands of automation with limited interconnectivity and limited ability to control complex interactions between systems. The current fleet of light water reactors, similar to U.S. industrial plants built during the same period, employ a mix of analog and digital instrumentation and controls (I\&C). Safety significant systems typically use analog instrumentation, and balance of plant systems have often been upgraded to digital I\&C. With HTGRs in the early phases of design, opportunities exist to both provide an integrated approach to plant instruments, controls, and automation and also to employ features of resilient control systems.

A resilient system can be defined as "one that maintains state awareness and an accepted level of operational normalcy in response to disturbances, including threats of an unexpected and malicious nature." The framework for a resilient control system contains principles and methods that proactively recognize threats, integrate automation and human response, provide robust and adaptive mechanisms, consider all threats and events, and tailor information to the consumer. These methods and principles improve a system's ability to anticipate, perceive, respond, and adapt. Improvements to these four abilities increase the system's overall ability to perform its necessary functions and operate resiliently. As this report shows, control systems with adequate levels of resilience perform at higher levels and respond more quickly to disturbances. The intent of this study was to develop an overall strategy for applying resilient controls to HTGRs to accomplish the following:

- Protect the capital investment associated with key systems within each of the HTGR plant areas

- Enhance the efficient operation of key systems individually and collectively given the complex interactions across systems and areas

- Identify and prioritize resilient functions for which HTGRs could most benefit from focused R\&D, engineering analysis, and licensing awareness.

\subsection{Results}

INL report INL/EXT-10-19359, Next Generation Nuclear Plant Resilient Control System Functional Analysis, was issued on July 21, 2010, to document the results of a detailed review of the existing knowledge base regarding functional analysis of resilient control systems as applied to HTGRs. The analysis included identification of significant gaps existing between traditional and resilient controls. The functional analysis report was then used to develop and inform the overall strategy for application of resilient controls to HTGRs.

INL report INL/EXT-10-19645, HTGR Resilient Control System Strategy, was issued on September 13, 2010, and outlines the overall strategy. In addition to the discussions of definition of resilient controls and gaps that exist between traditional and resilient control systems, this report provides a number of specific scenarios where resilient controls might influence HTGR design.

INL submitted letter CCN 220565, "Completion of Level 2 Milestone - Issue Report on Resilient Control System Strategy," to DOE-NE on September 13, 2010 to document the completion of Level 2 Milestone M2GIN10NG0703a23. 
Discussion: Control systems with adequate levels of resilience will perform at higher levels, respond more quickly to disturbances, provide more efficient operations, and increase public protection over a traditional control system. Since HTGRs are still in the early stages of design, there is an opportunity to build resilience into the planned I\&C systems as an integrated, as opposed to "bolt-on," feature. Some additional research will be necessary to develop particular areas of interest to HTGRs. Resilient research areas of particular interest to HTGR include:

- Cyber and physical security

- Process stability and efficiency

- Integration of diverse indicators

- Interlacing of human and automatic responses. 


\section{WATER INGRESS ANALYSIS}

\subsection{Purpose}

In FY 2007, during the NGNP preconceptual design phase, the NRC, in collaboration with DOE, conducted multiple Phenomena Identification and Ranking Table (PIRT) exercises using panels of technical experts covering major topical areas relevant to NGNP safety and licensing. During these exercises, the panel associated with accident analysis and thermal fluids (ACTH) decided to eliminate a steam-water ingress event from the accident types under consideration because the proposed plant configurations under review did not have an option for a steam generator in the primary loop, thereby removing the potential for a significant steam-water ingress event caused by steam generator leakage, and no other substantial water-steam ingress events could be postulated (NUREG/CR-6944 2008). In the Design Development studies phase following preconceptual design, however, the reactor design suppliers for the prismatic block reactor established that their preferred configuration was to include a steam generator in the primary loop, as opposed to an IHX. Following the recommendation from the Senior Advisory Group (SAG) in October of 2008 to reduce the proposed ROT from $950^{\circ} \mathrm{C}$ to a range of 750 $800^{\circ} \mathrm{C}$ (SAG 2008), steam generators were introduced into the primary loop for the reference configurations proposed by both the pebble bed and the prismatic block reactors. NGNP Engineering also anticipates that the configurations proposed by the offerors to the FOA included steam generators in the primary loop. Therefore, the reference configurations, as currently proposed, did not have the benefit of the PIRT process to assess the safety performance of the NGNP and to identify the analytical tools and additional research that would be needed to support the safety analysis and design efforts. The NGNP Project intends to apply a PIRT-like process to a steam-water ingress event. This work scope was proposed and approved via BCP 10-CQ-008 in June 2010. As this effort is not conducted by the NRC, the evaluation is being designated as a "conceptual PIRT," or CPIRT.

The water-ingress analysis effort will be carried into and completed during FY 2011.

\subsection{Results}

As of the end of FY 2010, the status for the water-ingress analysis effort is as follows:

- A charter for the CPIRT committee has been drafted

- A chairman for the CPIRT committee has been identified and an SOW has been drafted. The selected CPIRT committee chairman was a member of the original PIRT panel expert team, and had acted as the chairman of the ACTH panel.

- A generic SOW for CPIRT committee members has been drafted

- A generic SOW for support from the reactor design suppliers has been drafted

- A date and place for the initial evaluation meeting has been tentatively established for the second week of January 2011 in Salt Lake City, UT. 


\section{CONCLUSION}

The Engineering Analysis work package accomplished a number of activities in FY 2010 that will help to inform Licensing, R\&D, and detailed design activities that will be performed during the preliminary design phase in Phase 2 of the NGNP Project. These activities were in the following areas:

- Fission Product Transport

- DDN Update and Consolidation

- Gas Reactor Lessons Learned Review

- Reactor Coolant Chemistry Control

- Resilient Control Systems for High Temperature Gas-cooled Reactors

- Water-ingress Analysis.

The activities associated with the Engineering Analysis work package accomplished a total of four Level 2 (external) milestones and two Level 4 (internal) milestones. These milestones are summarized in Table 1.

Table 1: Engineering Analysis FY 2010 milestones.

\begin{tabular}{|l|c|l|l|}
\hline \multicolumn{1}{|c|}{ Milestone No. } & Level & \multicolumn{1}{c|}{ Title } & \multicolumn{1}{c|}{ Satisfied by } \\
\hline M2GIN07NG0705 & 2 & Complete Fission Product Transport Report & $\begin{array}{l}\text { GA 911168 } \\
\text { WEC NGNP-PLD- } \\
\text { GEN-RPT-N-00007 }\end{array}$ \\
\hline M2GIN10NG0703a25 & 2 & Issue Gas Reactor Lessons Learned Report & INL/EXT-10-19329 \\
\hline QB10259M & 4 & Reactor Coolant Chemistry Control Report & INL/EXT-10-19533 \\
\hline QB10273M & 4 & Resilient Controls Functional Analysis Report & INL/EXT-10-19359 \\
\hline M2GIN10NG0703a23 & 2 & $\begin{array}{l}\text { Issue Report on Resilient Control Systems } \\
\text { Strategy }\end{array}$ & INL/EXT-10-19645 \\
\hline M2GIN10NG0703a21 & 2 & $\begin{array}{l}\text { Status report summarizing the progress made in } \\
\text { Engineering Analysis during FY 2010 }\end{array}$ & INL/EXT-10-19772 \\
\hline
\end{tabular}

Note that issuance of this report satisfies the requirements of the final milestone listed in Table 1. 


\section{FUTURE EXPECTATIONS}

The Engineering Analysis work package is not planned for inclusion in NGNP Engineering FY 2011 work scope. Follow-on activities related to fission product transport will be addressed during unit dose estimate work scope in the NGNP Regulatory Affairs control account. The effort to implement lessons learned in NGNP planning will be addressed in the NGNP Systems Engineering work package as part of risk register and Technology Development Roadmap related activities. The effort for water-ingress analysis will performed as FY 2010 carryover work scope in the NGNP Project Engineering work package. The follow-on effort for all other FY 2010 Engineering Analysis activities will be addressed in future fiscal year planning once Phase 2 of the NGNP is underway and some specific design selections have occurred. 


\section{REFERENCES}

Financial Assistance Funding Opportunity Announcement Number DE-FOA-0000149, issued by DOEID, September 18, 2009.

INL, 2010a, NGNP Fuel Qualification White Paper, INL/EXT-10-17686, Idaho National Laboratory, July 2010.

INL, 2010b, Mechanistic Source Terms White Paper, INL/EXT-10-17997, Idaho National Laboratory, July 2010.

NUREG/CR-6839, Fort Saint Vrain Gas Cooled Reactor Operational Experience, ORNL/TM-2003/223, D. A. Copinger and D. L. Moses, Oak Ridge National Laboratory, published in January 2004.

NUREG/CR-6944, Next Generation Nuclear Plant Phenomena Identification and Ranking Tables (PIRTs), Vol. 6, ORNL/TM-2007/147, Vol. 6, C. W. Forsberg (panel Chair), Oak Ridge National Laboratory, published March 2008.

SAG, 2008, "Reference Configuration Meeting Minutes," NGNP Senior Advisory Group, Crystal City, VA, October 28, 2008. 